\title{
Will the real security foresight expert please stand up?
}

\author{
Sarah Lohmann • Tim Tepel
}

Received: 5 December 2013 / Accepted: 20 February 2014 / Published online: 29 March 2014

(C) The Author(s) 2014. This article is published with open access at Springerlink.com

\begin{abstract}
In its critical comparative overview of foresight methods and how they are used by different futures institutes in Europe, North America, and their partners, the text argues that while many futures institutes claim to provide foresight expertise, few actually provide the tools needed by policy makers to help prepare for security risks. It identifies two trademarks of genuine security foresight experts: 1.) They will differentiate between trends and futures research 2.) Their methods will have met with success in providing early warning signals. These methods often come from the fields of statistical analysis and computer simulation, but can be enriched by human judgment which tests modeling results in the real world.
\end{abstract}

Keywords Foresight - Security risks · Crisis early warning · Agent-based modeling $\cdot$ System dynamics $\cdot$ Futures institutes

In a globalized era where futures studies can provide warning signals for security threats, cooperation among the major futures studies players in Europe and its allies in North America and beyond is vital. Civil unrest, ethnic conflict, terrorist attacks, or state-led discrimination can have an impact on the security of neighboring states or even strategic partners a continent away. Yet while those claiming to have foresight prowess have created lucrative business opportunities, not all groups use scientifically reliable methods useful for

Dr. Sarah Lohmann and Tim Tepel (M. Sc.) are on the Faculty of Governance and Social Sciences' Institute for Political Science at the Universität der Bundeswehr and conduct futures research for the Bundeswehr Planning Office.

S. Lohmann $(\bowtie) \cdot$ T. Tepel

Institut für Politikwissenschaft, Universität der Bundeswehr

München, Gebäude 33/Raum 2254, Werner-Heisenberg-Weg 39,

85577 Neubiberg, Germany

e-mail: sarah.lohmann@unibw.de

T. Tepel

e-mail: tim.tepel@unibw.de preventing security risks. Making unified progress on security policy and global cooperation between institutes even more difficult, many institutes use futures research vocabulary differently. This article discusses the methodology and futures lingo used by foresight companies and institutes. Specifically, it focuses on an overview of which of their quantitative methods can provide early warning mechanisms in military and political security. ${ }^{1}$

In scanning the literature provided by futures institutes about themselves, as well as their publications, two main observations stand out: 1.) While "pop futurism" confuses popular trends with futures research, the genuine expert will know the difference [2]. 2.) One can identify the real security foresight specialist by his or her use of methods that have met with success in providing early warning signals. These methods often come from the fields of statistical analysis and computer simulation, but can be enriched by human judgment which tests modeling results in the real world.

\section{Different lexicons}

Among the most common vocabulary used interchangeably are "trends" and "futures research" [2]. While trends are a movement in one specific direction over time $[3,4]$ with a duration of 3 to 5 years [5], futures research is an interdisciplinary approach to "gaining understanding of how today's conditions and trends will likely shape the future (...) and how the future conditions could be shaped by policies and actions taken (...) today" [6].

\footnotetext{
${ }^{1}$ In this article, we focus on futures methods concerned with assisting military and political security. Paul Williams defines "military security" as the "interplay between the armed offensive and defensive capabilities of states," and political security as "focused on the organizational stability of states, systems of government and the ideologies that give them their legitimacy" [1, p. 4].
} 
Many companies believed they were conducting futures research when actually they were merely looking at trends in market values, stock shares, or cultural mores. For this purpose, our interdisciplinary team has created a glossary containing definitions used by the Futures Research community, and has highlighted one, streamlined definition which can be used by anyone conducting research in the field of futures research (view glossary here: www.unibw.de/ internationalepolitik/projekte/projekte/Zukunftsanalyse/) [7].

When governments want to find a futures institute which can advise them on security issues, they will need to sort through the countless institutes with "futures" in the name which perform more qualitative research, with the aim of either looking at trends, as opposed to forecasts or early warning systems, or at self-realization techniques such as "visioning," which helps one envision a utopian future for oneself or one's company.

While many futures institutes, such as the World Future Society, the Centre for Futures Studies and the Foresight Institute offer the "Delphi" technique, which consists of convening a panel of experts to analyse trends or make future predictions, the predictions made by these experts are only as accurate as the methods used by each. Other institutes, such as Kairos Future in Stockholm, tout the use of "road mapping," a visualization of a future goal based on the metaphor of navigation. Institutes such as Tamkang University or The Futures Academy in Dublin use a "futures wheel," which refers to the visualization of the consequences of trends through diagramming them on a wheel. ${ }^{2}$ These methods do not necessarily provide warning signals for the future so much as they are simply a diagram or visualization of goals, desires and outcomes.

\section{Futures methods helpful for security foresight}

Partnerships between futures institutes in Europe, the United States and Asia can be strengthened to assist in crisis planning and early warning systems for the prevention of national security and economic threats. This requires openness to using different futures methodologies and a knowledge of which methods are most helpful in predicting security risks. In addition to using a different futures lexicon, the institutes use very different methodologies.

While early futures institutes produced futures research methods such as scenarios or computer simulations for defense purposes, by the time futures research giant Theodore Gordon had founded several of the first U.S. futures think tanks, it became clear that distinctions were needed for

\footnotetext{
${ }^{2}$ See Universität der Bundeswehr München's Futures Studies Glossary under : www.unibw.de/internationalepolitik/projekte/projekte/ Zukunftsanalyse/.
}

different methodologies $[8,9] .{ }^{3}$ Gordon differentiated between quantitative and qualitative methods, and between exploratory and normative methods [10].

Quantitative methods are "mathematically based, using equations and precise measuring instruments, and are illustrated by methods such as time-series analysis, the cohort/ component method, computer simulations, and survey research" [8, p. 243].

Qualitative methods, on the other hand, do not rely on numbers or statistical analyses. Methods such as business gaming, causal layered analysis, simulation, and Delphi are frequently used by foresight think tanks, but foresight experts in the security field will not use these alone to make accurate security predictions. They can be used as a second layer to complement other quantitative methods. Methods may also include a mix of both, when empirical data is used for speculative purposes. While quantitative methods may be more easily assessed for their reliability, a mix of methods can also provide a researcher with a greater number of future alternatives. Here is an outline of the top methodologies used for security foresight, and the strengths and weaknesses of each. To find out a more complete list of which institutes use these methodologies, visit: www.unibw.de/internationalepolitik/ projekte/projekte/Zukunftsanalyse/.

\section{Quantitative futures methods}

Most futures institutes rely on qualitative methods for their forecasts. However, a handful of the most respected futures institutes, such as RAND [9], the Fund for Peace and RAHS Singapore have based their research or software on combinations of qualitative and quantitative methods. Research and tools from these institutes are being used by governments to receive early warnings when energy, economic and demographic changes are about to lead to crisis, or to predict failed states, violent conflict, and government instability. One mark of the real security foresight expert is his or her ability to create, use or contribute to software which is able to either simulate the future on the computer, or make projections based on statistical analysis. Below is a list of the methods best suited to security foresight when using statistical methods on the one hand, or computer simulation methods on the other.

\section{Statistical methods}

Statistical methods are being used by futures institutes to make long term projections or produce early warning systems for policy makers in the security field. These include interfaces or

\footnotetext{
${ }^{3}$ Gordon's think tanks include Institute for the Future and The Futures Group, which grossed \$20 million per year by 1990 .
} 
software using methods such as time series analysis and indicator-based models employing real world data for the explanatory variables.

\section{Indicator-based models}

Commonly employed modeling methodologies using indicators generated from real world data include logistic regression models, artificial neural networks, and other classification algorithms. Indicators generated from real world data have also been employed as part of early warning indices that do not explicitly model the relationship between a set of independent variables and a dependent variable.

The Fund for Peace's annual "Failed States Index" is an example of such an index. The indicators used in the index, such as the legitimacy of the state and the security apparatus, demographic pressure, and development, measure state weakness. While the Failed States Index is not a forecasting tool, it allows for the identification of security risk factors across countries and time periods [11]. ${ }^{4}$

Indicator-based models have also been developed for gaining insights into the economic and political cause of conflict onset, as well as explicitly for forecasting purposes. ${ }^{5}$ Recently developed crisis early warning models such as those produced by Goldstone, Bates, Epstein, et al. (2010) are examples of models using structural indicators to help determine when civil war or adverse regime change might occur. While far from producing outstanding results when tested against small observation windows, they have increased accuracy when considering longer observation windows, for example, by asking whether a certain country would experience an instability event within the next 5 years rather than in 2 years from now. Goldstone et al. have even produced several models that are able to predict state failure or civil war with $80 \%$ accuracy 2 years in advance $[12,13]$.

The questions policy-makers need to answer with respect to the specification of such models are: Is a high rate of false positives worse than a missed failure case? How many times more "costly" is it to miss out on a future failure case than to misclassify a country that will remain stable?

With respect to the policy-relevant implications of existing forecasting models, one striking finding is that "partial democracies" were found to be at significantly increased risk for

\footnotetext{
${ }^{4}$ Senior Researcher Nate Haken was also interviewed on the crafting of the Failed States Index at the Fund for Peace by the Universität der Bundeswehr on October 8, 2013.

${ }^{5}$ For studies on the causes of conflict, see: [50-53]. For models explicity developed for forecasting purposes, see: [12-14, 19, 49, 54].
}

the onset of different types of political crises such as civil war, adverse regime changes, and political instability than either full democracies or autocracies across a range of studies [12-15]. Future policy-oriented research among cooperating futures institutes could thus shed further light on the question of which causal dynamics lead to instability onsets and to what extent external influences could mitigate the risk of instability onsets in these countries.

\section{Times series models}

Times series models are used by institutes such as the Copenhagen Institute for Futures Studies, Stanford Research Institute, Virtual Research Associates, the Naval Postgraduate School and Tamkang University to collect and analyse historical quantitative data in a specific area. A mathematical form is found for relating one parameter, such as time, to another. Their emphasis lies on forecast accuracy rather than on causality.

For example, Virtual Research Associates has produced the GeoMonitor to help predict indicators with relationship to country stability. It produces an automated rating of news updates, and converts indexes with the possibility of graphing the interaction between individual countries and groups of countries. Its prospects tool also uses historic structural data of a country to develop and optimize algorithms for the prediction of long term country stability.

Time series models are helpful in producing mid- to longterm predictions for time series that exhibit low levels of volatility, such as certain demographic or economic variables. Time series models have also seen applications in security forecasting in the past, in particular as part of event data-based crisis early warning models $[16,17]$. Within these models, time-series analysis is used to extrapolate time series data into the future on average levels of conflict and cooperation present within a specific country or among specific actors.

Time series analysis can also produce an initial forecast, and then be improved by using qualitative analysis as an interim step. For example, the initial extrapolation data can be analyzed by numerous regional experts who input additional variables and nexus points and rerun the formula to make a more detailed extrapolation of indicators having ramifications for security.

\section{Computer simulation methods}

Agent-based models

Agent-based models have been used by institutes such as the Institut Futur in Berlin and the Defense Advanced Research Projects Agency-financed Integrated Crisis Early Warning 
System. An agent-based model is a computational model which simulates interactions between agents in a given static or dynamic environment in order to evaluate the system as a whole [18, p. 172-216]. The Integrated Crisis Early Warning System used agent-based models to forecast the occurrence of various types of conflict for 28 countries in the US Pacific Command [19, p. 96]. ${ }^{6}$

Agent-based models in general are most useful for studying behavioral rule-based processes that lack central coordination and that are characterized by a high degree of localization and distribution and dominated by discrete decisions [20, p. 24]. However, these models were not developed for forecasting purposes and are more concerned with explaining events than predicting them [21, p. 146-147].

Agent-based modeling has also been frequently used in political science to explain the occurrence and progress of internal crisis such as insurgencies, rebellions, and civil war [e.g. 22-29]. The overall forecasting validity is difficult to assess, since future observations are by nature impossible, and if verification is done based on past events, data can be skewed.

\section{System dynamics}

System dynamics, first conceived as a modeling methodology by MIT's Jay Forrester, is a theory of system structure and a set of tools used in identifying, depicting and analyzing multiloop, nonlinear feedback relationships [30]. It was initially developed to analyze management problems and industrial processes, but is now used by futures institutes to analyze social and political phenomena.

Institutes such as the Universität der Bundeswehr's COMTESSA have used it to examine what Germany's Electricity industry will look like in 2025 and to gain foresight for worldwide energy alternatives, which helps allies' security planning on a global scale [31].

Since system dynamics is good at modeling complex interdependencies and for policy analysis and design, it can provide highly accurate forecasting performance if functional relationships are properly modeled. System dynamics has seen applications with security-relevant implications in the past. For example, it has frequently been used to explain the occurrence and development of insurgencies, in explaining the behavior of insurgent groups, and in analyzing future prospects for country stability [32-39]. It can be used to model combat, examine the prospects for the occurrence of nefarious technology development in specific countries, and for generating scenarios for the future development of key industries within a specific country [40-43].

\footnotetext{
${ }^{6}$ The ICEWS-project attempted to forecast rebellions, insurgencies, domestic political crises, ethnic/religious violence, international crises and an index of instability for 28 countries.
}

\section{Scenarios}

Scenarios are useful for futures institutes working with government planners, corporate strategists and military analysts. Institutes such as RAND use the method as it is useful for military and security planning for middle to long-term forecasting, where unexpected events or discontinuities could play a large role. They are not useful if one has little time, one needs an exact forecast, or a clear methodology is needed.

Herman Kahn, who founded the Hudson Institute, is considered the father of scenario methods. He invented the method while working at RAND in connection with military and strategic studies [44, 45]. Specifically, he looked at scenarios in which nuclear war could be possible, what its fallout would be, and what possible responses could be. Today, such scenarios can be used as part of a computer simulation to evaluate alternatives to pre-programmed parameters, events, and interactions [46].

\section{Wild cards}

A major obstacle in any futures research is related to how to incorporate wildcards and weak signals into the analysis. Weak signals are small changes that are currently observable but may only trigger bigger changes in the future. These can be incorporated into statistical models, where accounting for certain destabilizing events in conjunction with latent structural risk factors may allow for the early-warning of an impending political crisis [47]. Likewise, unexpected outcomes may result from agent-based simulations as emergent phenomena due to micro-level interactions with initially unclear implications.

In contrast, wild cards are events that cannot be predicted or fully anticipated, but at the same time, have the potential to "alter the international system by their reversal of significant trends, thereby undermining the facts upon which future planning is built" [48]. Since the probability for their occurrence and in many cases their exact nature will be unknown, they are difficult to incorporate into statistical models and computer simulations. Nevertheless, a real security foresight expert must leave room to calculate the unknowns. Nate Silver does this by assigning a value to epistemological uncertainty - "the limits of our knowledge" [29]. By using Bayer's Theorem, he is able to calculate the posterior probability of a previously unknown event. This involves assigning a value to the prior probability and a value to a new event occurring or not, to come to the posterior probability [29]. He recommends integrating this method into computer simulations, but only in a limited way - for running tests on all possible options. Human judgment is then indispensable for testing the computer predictions in the real world, rather than within the comfortable confines of a model, to improve accuracy [29]. 


\section{Conclusion}

As security threats make continental divisions less important, futures institutes should have more incentive to provide organizations such as NATO and the EU with the early warning technology they need to protect our common interests. The models may differ in methodology, or use a combination of methodologies to make more accurate predictions.

While indicator-based models have produced highly accurate early warning results $y$, system dynamics models or agentbased models have also been shown to be helpful for helping policy makers make security predictions. Those who combine the benefits of modeling with human judgment, allowing for the unexpected, are best placed to aid in security foresight. As institutes become more interested in lending their expertise to foresight projects which contribute to our common security, policy makers will be better enabled to prevent risks. This will help them capitalize on conflict resolution opportunities which have the power to expand stability and keep our communities safe.

Open Access This article is distributed under the terms of the Creative Commons Attribution License which permits any use, distribution, and reproduction in any medium, provided the original author(s) and the source are credited.

\section{References}

1. Williams PD (2013) Security studies: an introduction. Routledge, London

2. Voros J (2001) A primer on futures studies, foresight and the use of scenarios. Prospect, the Foresight Bulletin, No 6, Swinburne University of Technology. http://thinkingfutures.net/resources/ futures-foresight/a-foresight-primer/foresight-primer/. Accessed 16 Feb 2014

3. Horx M (2010) Trends definition. Horx Zukunftsforschung GmbH. http://www.horx.com/zukunftsforschung/Docs/02-M-03-TrendDefinitionen.pdf. Accessed 1 November 2013

4. Horx M, Huber J, Steinle A, Wenzel E (2007) Zukunft machen. Wie Sie von Trends zu Business Innovationen kommen. Ein Praxis Guide. Frankfurt a.M, Germany

5. Van der Duin P (2006) Qualitative futures research for innovation. Eburon Academic Publishers, Amsterdam

6. Getz D (2007) Event studies. Theory, research and policy for planned events. Routledge, London, UK

7. Universität der Bundeswehr München's Futures Studies Glossary. http://www.unibw.de/internationalepolitik/projekte/projekte/ Zukunftsanalyse/. Accessed 1 December 2013

8. Bell W (2010) Foundations of futures studies: human science for a new era: history, purposes, knowledge. Transaction Publishers, Piscataway

9. RAND History and Mission. http://www.rand.org/about/history. html. Accessed 20 November 2013

10. Gordon TJ (1992) The methods of futures research. Annu Am Acad Polit Soc Sci 522(1):25-35

11. Null S, Lamere C (2012) What are the most important factors in the Failed States Index? New Security Beat, The Wilson Center. http:// www.newsecuritybeat.org/2012/06/what-are-the-most-importantfactors-in-the-failed-states-index/\#.UpXQGuIsazE. Accessed 1 November 2013

12. Goldstone JA, Gurr TR, Harff B, Levy MA, Marshall MG et al. (2000) State failure task force report: phase III Findings. Center for International Development and Conflict Management. http://www. cidcm.umd.edu/publications/papers/SFTF\%20Phase $\% 20 \mathrm{III} \%$ 20Report $\% 20$ Final.pdf. Accessed 15 June 2013

13. Goldstone JA, Bates RH, Epstein DL, Gurr TR, Lustik MB et al (2010) A global model for forecasting political instability. Am J Polit Sci 54(1):190-208

14. King G, Zeng L (2001) Improving forecasts of state failure. World Polit 53(4):623-658

15. O'Brien SP (2002) Anticipating the good, the bad, and the ugly: an early warning approach to conflict and instability analysis. J Confl Resolut 46(6):791-811

16. Brandt PT, Freeman JR, Schrodt PA (2011) Real time, time series forecasting of inter- and intra-state political conflict. Confli Manag Peace Sci 28:41-64

17. Pevehouse JC, Goldstein JS (1999) Serbian compliance or defiance in Kosovo? Statistical analysis and real-time predictions. J Confl Resolut 43(4):538-546

18. Gilbert N, Troitzsch KG (2005) Simulation for the social scientist. Open University Press, Berkshire

19. O’Brien SP (2010) Crisis early warning and decision support: contemporary approaches and thoughts on future research. Int Stud Rev 12:87-104

20. Van Dyke Parunak H, Savit R, Riolo RL (1998) Agent-based modeling vs. equation-based modeling: a case study and users' guide. Proceedings of Multi-agent systems and Agent-based Simulation (MABS'98), 10-25. http://www.jacobstechnology.com/acs/pdf/ mabs98.pdf 10-24. Accessed 1 June 2013

21. Macy MW, Willer R (2002) From factors to actors: computational sociology and agent-based modeling. Annu Rev Sociol 28:143-166

22. Bennett DS (2008) Governments, civilians, and the evolution of insurgency: modeling the early dynamics of insurgencies. J Artif Soc Soc Simul 11(4):7

23. Bhavnani R, Backer D (2000) Localized ethnic conflict and genocide: accounting for differences in Rwanda and Burundi. J Conflict Resolut 44:283-306

24. Bhavnani R, Miodownik D, Nart J (2008) REsCape: an agent-based framework for modeling resources, ethnicity and conflict. J Artif Soc Soc Simul 11(2):7

25. Cioffi-Revilla C, Rouleau M (2010) MASON RebeLand: an agentbased model of politics, environment, and insurgency. Int Stud Rev 12(1):31-52

26. Doran J (2005) Iruba: an agent-based model of the guerrilla war process. In "Representing Social Reality", pre-proceedings conducted at the Third Conference of the European Social Simulation Association (ESSA), Koblenz, Germany. http://cswww.sx.ac.uk/ staff/doran/34.PDF. Accessed 1 June 2013

27. Epstein JM (2002) Modeling civil violence: an agent-based computational approach. Proc Natl Sci Acad Sci 99(3):7243-7250

28. Miodownik D, Bhavnani R (2011) Ethnic minority rule and civil war onset. Conflict Manag Peace Sci 28:438-458

29. Silver N (2012) The signal and the noise. Penguin Press, New York

30. Choucri N, Heye C (1990) Simulation models. Energy 15(4):363378

31. Arto K, Dolgopolova I, Hu B, Leopold A, Pickl S (2012) Germany's electricity industry in 2025: evaluation of portfolio concepts. The 2012 International Conference of the System Dynamics Society, Proceedings, St. Gallen, 22.-25 July, 2012. System Dynamics Society website. http://www.systemdynamics.org/conferences/2012/ proceed/papers/P1148.pdf. Accessed 5 June 2013

32. Anderson, EG (2006) A preliminary system dynamics model of insurgency management: the Anglo-Irish war of 1916-21 as a case 
study. System Dynamics Society website. http://www. systemdynamics.org/conferences/2006/proceed/papers/ANDER426. pdf. Accessed 1 June 2013

33. Arto K, Hu B, Leopold A, Meyer-Nieberg S, Mihelcic G, Stutzki J, Tepel, T (2014) Modellbasierende Früherkennung politischer Krisen: Prototyp einer serviceorientierten Plattform. Multikonferenz der Wirtschaftsinformatik, Paderborn, 26.-28 February, 2014

34. Ellis RE (2004) January/February) The impact of instability in Latin and South America. IEEE Eng Med Biol Mag 187-193

35. Enos JR, Farr JV (2013) State security dynamics and the impact of intervention to build country capacity. System Dynamics Society website. http://www.systemdynamics.org/web.portal?P1003+0. Accessed 13 June 2013

36. Grynkewich A, Reifel C (2006) Modeling Jihad: a system dynamics model of the Salafist group for preaching and combat financial subsystems. Strategic Insights, V (8)

37. Schoenwald D, Johnson C, Malczynski L, Backus G (2009) A system dynamics perspective on insurgency as a business enterprise. System Dynamics Society website: http://www.systemdynamics.org/ conferences/2009/proceed/papers/P1284.pdf. Accessed 1 June 2013

38. Sokolowski J, Banks C (2007) From empirical data to mathematical model: using population dynamics to characterize insurgencies. Proceedings of the 2007 Summer Computer Simulation Conference, 1120-1127. http://dl.acm.org/citation.cfm?id=1358085. Accessed 1 June 2013

39. Wakeland WW, Medina EE (2010) Comparing discrete simulation and system dynamics: modeling an anti-insurgency influence operation. System Dynamics Society website. http://www. systemdynamics.org/conferences/2010/proceed/papers/P1276.pdf. Accessed 1 June 2013

40. Anderson EG, Choucri N, Goldsmith D, Madnick S, Siegel M (2009) System dynamics modeling for pro-active intelligence (PAINT). Composite Information Systems Laboratory Working Paper CISL\#2009-17, MIT Composite Information Systems Laboratory. http://ecir.mit.edu/images/stories/Madnick\%20et\%20al_System\%
20 Dynamics $\% 20$ for $\% 20$ Pro-Active $\% 20$ Intelligence $\% 20 \%$ 28PAINT\%29.pdf. Accessed 1 June 2013

41. Artelli MJ, Deckro RF (2008) Modeling the Lanchester Laws with system dynamics. J Def Model Simul 5:1-20

42. Chen JH, Jan TS (2005) A system dynamics model of the semiconductor industry development in Taiwan. J Oper Res Soc 56(10): $1141-1150$

43. Coyle JM, Exelby D, Holt J (1999) System dynamics in defence analysis: some case studies. J Oper Res Soc 50:372-382

44. Glenn JC "Scenarios". In: AC/UNU Millenium research project, futures research methodology V 2.0

45. Kahn H, Wiener AJ (1967) The year 2000: a framework for speculation on the next thirty-three years. Macmillan, New York City

46. Alexander IF, Maiden N (2004) Scenarios, stories, use cases. John WIley \& Sons, Hoboken

47. Tikuisis P, Carment D, Samy Y (2012) Prediction of intrastate conflict using state structural factors and event data. J Confl Resolut 57(3):410-444

48. Tangredi SJ (2000) All possible wars? Toward a consensus view of the future security environment, 2001-2015. Institute for National Strategic Studies, Washington, D.C., p 119

49. Beck N, King G, Zeng L (2000) Improving quantitative studies of international conflict: a conjecture. Am Polit Sci Rev 94(1):21-35

50. Blimes RJ (2006) The indirect effect of ethnic heterogeneity on the likelihood of civil war onset. J Conflict Resolut 50(4): 536-547

51. Buhaug H, Rød JK (2006) Local determinants of African civil wars, 1970-2001. Polit Geogr 25:315-335

52. Collier P, Hoeffler A (2004) Greed and grievance in civil war. Oxf Econ Pap 56(4):563-595

53. Fearon JD, Laitin DD (2003) Ethnicity, insurgency, and civil war. Am Polit Sci Rev 97(1):75-90

54. Rost N, Schneider G, Kleibl J (2009) A global risk assessment model for civil wars. Soc Sci Res 38(4):921-933 